\title{
História da Educação Rural: formação e trabalho docente no Brasil no Século XX
}

Historia de la Educación Rural: formación y trabajo docente en Brasil en el Siglo XX

History of Rural Education: teacher training and work in Brazil in the 20th century

Kamila Cristina Evaristo Leite

Universidade Estadual Paulista (Brasil)

https://orcid.org/0000-0003-0983-1727

http://lattes.cnpq.br/6015545696698130

Kamila89.leite@gmail.com

Tiago Rodrigues da Silva

Universidade Estadual Paulista (Brasil)

https://orcid.org/0000-0002-8325-7340

http://lattes.cnpq.br/7913297134958091

tiago.r.silva@unesp.br

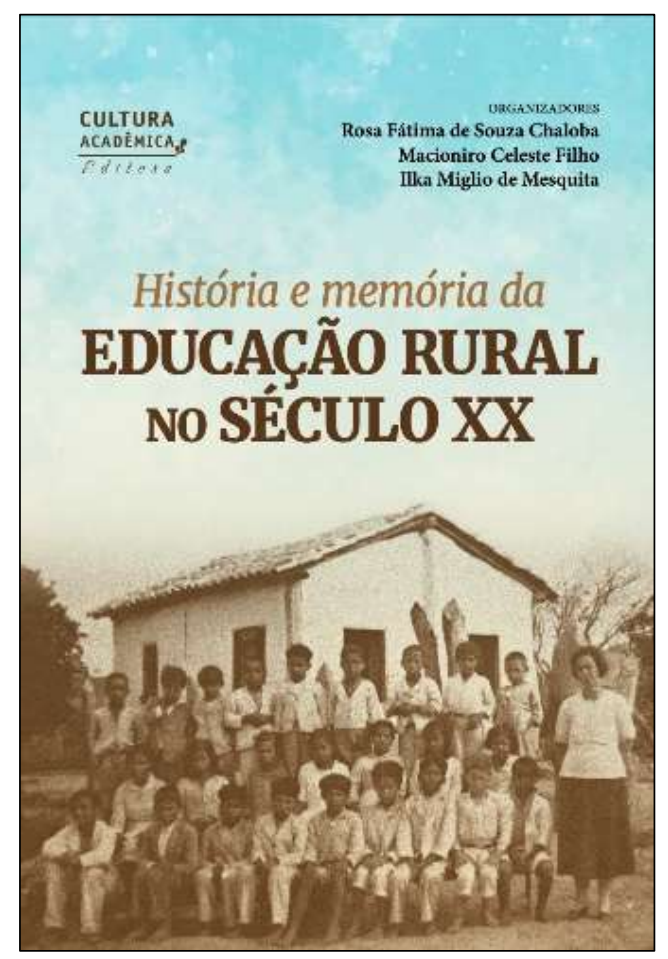

CHAlOBA, Rosa Fátima de Souza; CELESTE FILHO, Macioniro; MESQUISTA, Ilka Miglio de (org.). História e memória da Educação Rural no Século XX. São Paulo: Cultura Acadêmica, 2020. 
Com a imagem de uma escola rural de Itapetininga, interior do Estado de São Paulo, do início dos anos 1930, a obra, História e memória da educação rural no século XX $X^{1}$, lançado em 2020, estampa a representação cultural da educação rural no país: a professora em uma casa improvisada para o estabelecimento de ensino das primeiras letras, com as salas multiseriadas e os alunos descalços. O livro resenhado reúne reflexões de um grupo de pesquisadores de distintos estados brasileiros que se ocuparam da formação e trabalho docente de professoras primárias rurais, no período compreendido entre 1930 a 1970, na perspectiva transversal, conectando o regional com o nacional, com as proposições da História Cultural e as abordagens da História e Educação Comparada.

Rosa Fátima de Souza Chaloba, Macioniro Celeste Filho e Ilka Miglio de Mesquista foram os responsáveis pela organização da obra com resultados do projeto de pesquisa nacional "Formação e Trabalho de Professoras e Professores Rurais no Brasil: RS, PR, SP, MG, RJ, $M S, M T, M A, P E, P I, S E, P B, R O$ (décadas de 40 a 70 do século $X X$ )'”. A pesquisa, coordenada por Rosa Fátima de Souza Chaloba, com financiamento do Conselho Nacional de Desenvolvimento Científico e Tecnológico (CNPq) objetivou compreender no âmbito do nacional e regional a formação do magistério rural e o trabalho docente (recrutamento, salários, carreira, etc.) em meados do século XX. A equipe do projeto contou com 18 instituições de ensino superior do país, envolvendo pesquisadores de reconhecida liderança no campo de História da Educação. Na assessoria internacional, houve intensa participação de Oresta López Péres, professora-pesquisadora titular do El Colegio de San Luis (COLSAN), em San Luis Potosi, México, assinando o prólogo "Processos históricos de construcción de identidade y resistencia de la educación rural en Brasil durante el siglo XX”.

Com tamanha pluralidade de experiências e fontes históricas, a produção, por meio de uma narrativa instigadora que conduz a reflexões acuradas sobre a educação rural no século passado, foi organizada em quatro partes: 1) balanço historiográfico; 2) referências externas e circulação de modelos; 3) formação docente; e 4) memórias e representações da docência nas escolas primárias rurais. As articulações em torno dos quatro eixos contribuem para o avanço do conhecimento histórico acerca da relação entre escola e ruralidade, profissionalização docente rural e história comparada da educação no Brasil.

A primeira parte, com três textos, demarca, com precisão, o Estado da Arte sobre a educação rural, consolidando-a como objeto de pesquisa histórica. Nesse sentido, Sandra Cristina Fagundes de Lima abre os trabalhos com a pesquisa "Balanço da produção sobre o tema formação e trabalho de professores rurais nos anais do Congresso Brasileiro de História da Educação (CBHE): 2000-2017”. A autora argumenta o lugar da pesquisa histórica acerca da formação e trabalho de professores rurais no principal espaço de produção e divulgação de História da Educação no Brasil, demostrando seu espaço nas fronteiras do campo de pesquisas. Evidencia, portanto, a necessidade de desvendar a escolarização nas ruralidades brasileiras.

Segue-se com o texto de Odaléia Alves da Costa e Rosa Fátima de Souza Chaloba em "A produção sobre formação e trabalho de professores rurais em dissertações e teses (20012018 ”). As autoras realizam um balanço da produção acadêmica com base no Catálogo de teses e dissertações da Coordenação de Aperfeiçoamento de Pessoal de Nível Superior (CAPES). Os resultados põem em evidência o avanço das pesquisas sobre o tema nos últimos anos, contudo indica a carência de recortes específicos sobre a formação e trabalho docente no rural levadas pela União e em cada unidade federativa.

O balanço do Estado da Arte sobre formação e trabalho de professores rurais é encerrado com o texto "As pesquisas sobre educação rural nos periódicos especializados (1997-2019)" de Simone Burioli Ivashita. O estudo buscou uma identificação e categorização de artigos sobre

\footnotetext{
${ }^{1}$ A obra está disponível no site da editora Cultura Acadêmica em forma de E-book para download grátis. Disponível em: https://culturaacademica.com.br/catalogo/historia-e-memoria-da-educacao-ruralno-seculo-xx/. Acesso 19 mar. 2021.
} 
a educação rural nos periódicos ${ }^{2}$ brasileiros especializados e de maior circulação no campo de História da Educação brasileira. O empreendimento do estudo denota o esforço para o cenário investigativo das pesquisas sobre a educação rural, muito embora concentradas, maiormente, na história institucional das escolas primárias rurais.

Diante dos referenciais externos e circulação de modelos sobre a educação rural, a segunda parte do livro é iniciada com o texto "Movimento pela ruralização do ensino em âmbito internacional: cartas a Sud Mennuncci (1930-1940) " de Agnes Iara Domingo Moraes. Neste capítulo, a autora revisita o velho tema do Ruralismo Pedagógico, interpretando-o de forma inovadora e questionando as interpretações já instituídas. Com a constituição da rede de sociabilidades em torno de Sud Mennuncci, considerado a maior autoridade do Movimento pela Ruralização do Ensino no país, o estudo mostra que as ideias ruralistas para a educação foram mais amplas, densas e difusas do que se imaginava anteriormente, extrapolando as fronteiras nacionais.

Atento à compreensão das escolas normais regionais no Brasil, legitimadas pela Lei Orgânica do Ensino Normal, Flávio Anício Andrade no capítulo "O curso normal regional e a formação da professora primária rural" analisa as propostas do Estado Nacional na institucionalização de um estabelecimento de ensino próprio para a profissionalização do magistério rural. O autor concentra-se na compreensão que o curso normal regional fez parte do projeto econômico, político e cultural de inserção das populações rurais na formação social do país, representando um forte impulso na escolarização no interior do Brasil.

Em tempos que o México foi posto como o maior exemplo da educação rural na América Latina, Rony Rei do Nascimento e Ilka Miglio de Mesquita no capítulo “'Educación rural con un espíritu social más que pedagógico?' O Crefal e as experiências de Educação Fundamental no México e Brasil (1950-1960)" trata das experiências da Educação Fundamental desenvolvidas pelo Centro Regional de Educación Fundamental para la América Latina (Crefal) com a Organização das Nações Unidas para a Educação, a Ciência e a Cultura (UNESCO) foram circuladas e conectadas como exemplares para o Brasil, principalmente, por meio de Lourenço Filho.

Em "A educação rural delineada por organismos internacionais de cultura e suas repercussões no Brasil nas décadas de 1960 e 1970”, Marcioniro Celeste Filho explora as concepções de educação rural repercutidas pelos órgãos governamentais brasileiros, tendo em vista as publicações e recomendações da UNESCO, Comissão Econômica para a América Latina e o Caribe (CEPAL) e Organização dos Estados Americanos (OEA). Neste processo, o capítulo trata como a educação rural foi idealizada pelos organismos internacionais, concebida pelos economistas da UNESCO, as concepções representadas pela Cepal e como o Brasil foi situado no debate internacional sobre a educação da população rural.

No que diz respeito à formação para o meio rural, Antonio de Pádua Carvalho Lopes, Alessandra Cristina Furtado e Rômulo Pinheiro de Amorim, no capítulo "O professor rural como professor leigo: políticas de formação e o ofício docente no Piauí e Mato Grosso (1940-1970" analisam, de modo comparado, o processo de institucionalização da escola primária rural e das políticas de formação do professor leigo. Nas análises, a composição do professor leigo no quadro do magistério rural consiste em uma das muitas similaridades entre as unidades federativas, como também o financiamento do Instituto Nacional de Estudos e Pesquisas Educacionais (INEP) na construção de prédios escolares para uma interiorização das escolas normais. Contudo, as políticas de formação para o magistério rural também apresentam tons diferentes entre os estados, por exemplo: o Piauí, diferente do Mato Grosso, contou com um maior número de escolas normais regionais. Com a quantidade insuficiente de professores diplomados, o professor leigo torna-se uma figura central para compreensão da formação e trabalho docente na zona rural.

\footnotetext{
2 Periódicos selecionados: Revista de História da Educação (1997-2019); Revista Histedbr on line (20002019); Revista Brasileira de História da Educação (2001-2019); Cadernos de História da Educação (2002-2019).
} 
Eliana Oliveira Nunes de Azevedo, Iracema Santos Carvalho dos Anjos, Rosa Lydia Teixeira Corrêa, Thais Bento Faria e Virginia Pereira da Silva de Ávila são as autoras do texto "Politicas de formação de professores primários rurais nos estados do Paraná e de Pernambuco (1930-1960) ". Neste capítulo, as autoras analisam a implantação das políticas educacionais nos estados de Paraná e de Pernambuco na formação do magistério rural, no período de 1930 a 1960. Na lógica de comparação, Pernambuco institucionalizou as escolas normais rurais, por iniciativa privada de entidades confessionais, e o Paraná com a interiorização de escolas normais regionais, pelo poder público. Ambos os estados, sob a égide da Ruralização do Ensino.

A parte da obra sobre as políticas de formação docente para o rural é encerrada no texto "Iniciativas para formação do professorado rural na Paraíba, em Pernambuco e no Piauí (1930 a 1960)" de Antonio Carlos Ferreira Pinheiro, Manuela Garcia de Oliveira e Maria do Perpetuo Socorro Castelo Branco Santana. As análises mostram que as políticas governamentais para a formação de professores rurais assumiram peculiaridades em cada estado. Em Pernambuco as iniciativas em torno da formação dos professores rurais remetem aos anos 1920, na Paraíba a partir de 1930 e, no Piauí após a promulgação da Lei Orgânica do Ensino Normal, a partir de 1946. Nesse sentido, cada estado buscou a institucionalização de escolas normais regionais ou rurais para a profissionalização do magistério rural.

No último bloco do livro, aqui analisado, Memórias e representações sobre a docência nas escolas primárias rurais, os autores se debruçaram em resgatar as memórias, as vivências, as trajetórias, a formação e o fazer docente de professores e professoras rurais nos Estados analisados, por meio da metodologia da História Oral. Nos textos que compõem este último bloco, os pesquisadores analisaram 43 depoimentos de professoras e professores rurais, de cinco regiões do Brasil (MG, MS, MT, PE, PR, RS, SE e SP) com o objetivo de compreender as experiências formativas, os aspectos da atuação docente no meio rural, as práticas desenvolvidas e as relações com a cultura escolar.

Em Atuação docente no meio rural: cultura e práticas escolares, Analete Regina Schelbauer e José Edimar de Souza ao analisar os depoimentos de professoras e professores rurais em diferentes regiões do Brasil, destacaram as vivências e experiências desses mestres nas escolas primárias rurais brasileiras, descrevendo os modos como esses professores e professoras ensinavam no meio rural e a relação desses docentes com as comunidades rurais. A partir da análise dos depoimentos os autores conseguiram contar e representar com palavras e imagens o cotidiano nas escolas rurais, as táticas utilizadas para ensinar as crianças rurais e as relações pessoais e profissionais com as populações rurais que viviam entorno da escola.

Sobre a formação de professores rurais no Brasil (1940 - 1970): o que as memórias revelam, as autoras Áurea Esteves e Raylane Andreza Dias Navarro Barreto, analisaram as ambivalências do prescrito na legislação educacional com os depoimentos de professoras e professores rurais para compreender as experiências de formação e trabalho desses sujeitos. No critério de legislação, o destaque foi para a Lei Orgânica do Ensino Normal, de 1946, que recomendou, entre os três tipos de estabelecimento de ensino normal, o curso normal regional para a formação específica de professores rurais. Nas narrativas das experiências formativas ficou subentendido que a maioria dos professores rurais eram leigos, pois contavam apenas com a formação em nível primário, sendo pouco os docentes que realizaram uma formação específica para o magistério em escolas normais, normais rurais ou formação em nível superior.

Josemir Almeida Barros e Nilce Vieira Campos Ferreira autores de Pesquisa em História da Educação Rural: professoras e professores entre teias e contextos, escreveram o último capítulo que compõem o livro aqui analisado. Nessa finalização, os autores se debruçaram sobre o projeto de pesquisa e as pesquisas realizadas que deram origem ao livro, como também, sobre as narrativas das professoras e professores entrevistados, 
compreendendo a importância desses mestres na educação das crianças rurais e das memórias para a pesquisa histórica.

Cabe ressaltar que os autores/pesquisadores apresentaram uma análise consistente sobre tema abordado, utilizando-se de referenciais teóricos condizentes ao propósito das pesquisas. Outro aspecto positivo, é a diversidade em relação ao espaço geográfico de análises das políticas de formação do magistério rural e dos depoimentos das professoras rurais como fontes e objetos das pesquisas, o que certamente contribuí para uma compreensão das simetrias e dissimetrias das unidades federativas na educação rural em meados do século XX, entre o regional e o nacional.

Todavia, ressalvamos que as concepções de educação rural e políticas de formação de professoras e professores rurais no Brasil estejam bem identificadas nos capítulos, há uma falta de aprofundamento dos espaços institucionais de profissionalização para o magistério primário rural, ou seja, das escolas normais regionais e escolas normais rurais, por exemplo. Assim, História e memória da educação rural no século XX projeta a importância de descortinar a complexidade da cultura escolar destes estabelecimentos de ensino normal na História e historiografia da educação do país.

Apesar disso, a leitura do livro é indispensável para todos que se interessam pelas questões da educação brasileira, sobretudo, no meio rural. Como se percebe na obra, a educação rural em meados do século XX foi fruto de uma complexa teia de ações, debates e embates de instituições (nacionais e internacionais) e atores políticos e sociais. Pode-se dizer que História e memória da educação rural no século $X X$ traz o percurso dos anos em que a educação chegou à população do interior do país, permitindo uma compreensão da ação docente no processo de escolarização de crianças e jovens nas ruralidades brasileiras. 